\title{
Antibiotics in exacerbations of COPD: lessons from the past
}

\author{
M. Miravitlles, A. Torres
}

The controversy about the use of the adequate antibiotic therapy for exacerbations of chronic obstructive pulmonary disease (COPD) continues. The new antibiotics, particularly the fluoroquinolones, have been included in most guidelines based on their excellent in vitro activity against respiratory pathogens, optimal bronchial penetration and convenient regimens of administration. However, clinical trials have only demonstrated equivalence of fluoroquinolones to traditional antibiotics and no conclusive evidence exists of their superiority in clinical practice.

In this context, we must either accept that no differences exist between antibiotics in this indication or that the majority of studies performed so far are inadequate to demonstrate them. The authors firmly believe that the second statement is more likely to be true than the first [1]. In fact, observational studies suggested that moxifloxacin produces a faster resolution of symptoms of exacerbation in COPD patients compared with amoxicillin-clavulanate, clarithromycin or cefuroxime [2]. In addition, the direct costs of exacerbations treated with clarithromycin appeared to be higher than the costs associated with the use of moxifloxacin or amoxicillinclavulanate, due to the higher rate of relapse with the macrolide [3]. However, the definitive evidence of superiority derived from randomised, double-blind, clinical trials is scarce, and most guidelines recommend the new and supposedly more potent antibiotics for patients more at risk of relapse, based more on common sense rather than on scientific evidence, which is well recognised by the authors of the guidelines themselves $[4,5]$.

In an attempt to demonstrate differences in outcomes between a fluoroquinolone, levofloxacin, and clarithromycin, LODE et al. [6] in this issue of the Journal present the results of a randomised, double-blind, clinical trial in patients with exacerbations of COPD. This trial presents two strengths, in comparison with most of the trials performed previously: the inclusion of COPD patients and the use of time to the next exacerbation as the primary outcome measure. The inclusion of patients with simple (nonobstructive) chronic bronchitis in antibiotic trials should be avoided. Patients with chronic bronchitis used to represent the milder end of the spectrum of bronchial disease caused by tobacco smoking and some or most may have normal lung function. The likelihood of bacterial infection as a cause of exacerbation decreases in patients with better lung function [7]. Furthermore, the diagnosis of chronic bronchits is not reliable as an inclusion criterion. A recent study has shown that only $11.6 \%$ of individuals with self-reported chronic bronchitis really met the criteria for the disease, but even more surprisingly, only $12.5 \%$ of physician-confirmed cases of chronic bronchitis

Servei de Pneumologia, Institut Clínic de Pneumologia i Cirurgia Toràcica (IDIBAPS), Hospital Clínic, Barcelona, Spain.

Correspondence: M. Miravitlles, Servei de Pneumologia, Institut Clínic de Pneumologia i Cirurgia Toràcica (IDIBAPS), Hospital Clínic, Villarroel 170, 08036 Barcelona, Spain. Fax: 34 932275549. E-mail: marcm@separ.es really fulfilled the criteria [8]. It is surprising that, to be included in a clinical trial with bronchodilators, patients need to fulfil strict spirometric criteria, repeated several times and with the test performed by certified investigators under standard circumstances, whereas to be included in an antibiotic trial the patient just need to answer "yes" to the question "Did you have cough and sputum for at least 3 months in the last 2 yrs?", with the possibility of all sources of bias and the impossibility to verify the answer.

The use of time to the next exacerbation as a primary outcome of the trial demonstrates the importance of preventing exacerbations [9]. Treatments with tiotropium, long-acting $\beta_{2}$-agonists and/or inhaled corticosteroids have shown a reduction of $\sim 20-25 \%$ in the rate of exacerbations. It is reasonable to assume that a different approach, such as effective antibiotic treatment, may further reduce the rate of recurrence. Some evidence supports this hypothesis: 1) persistence of bacteria after antibiotic treatment for an exacerbation is associated with persistent bronchial inflammation [10]; 2) presence of bacteria in the airway (bronchial colonisation) is associated with more frequent and severe exacerbations [11]; 3) in a previous study, the presence of a persistent pathogen at the end of antibiotic therapy was significantly associated with a shorter infection-free period $(\mathrm{p}<0.01)$ [12]; and 4) another study showed superior bacterial eradication of moxifloxacin compared with standard therapy and this was followed by a prolonged infection-free interval that was significant for the first 5 months of follow-up [13]. Considering this evidence together, it can be hypothesised that effective antibiotic treatment that results in bacterial eradication may prevent recurrence, at least during the first months after the exacerbation, which is in agreement with the "fall and rise" hypothesis of bronchial bacterial infection [14]. Late recurrence may be better explained by changes in serotype of the infecting strains, as elegantly demonstrated by SETHI et al. [15].

In the study by LoDE et al. [6], there was a significantly better bacterial eradication with levofloxacin compared with clarithromycin; however, no significant differences were found in the exacerbation-free interval. This is in contrast with the previous studies with gemifloxacin [16] and moxifloxacin [13]. It is very unlikely that this discrepancy is caused by a lower efficacy of levofloxacin compared to the other fluoroquinolones, but is more likely due to the differences in the severity of the population studied. In the study by WILSON et al. [13], $45 \%$ of individuals had a forced expiratory volume in one second (FEV1) $<50 \%$ predicted, compared with only $28 \%$ in the present study. Furthermore, 36\% were neversmokers and only $10 \%$ and $20 \%$ were receiving treatment with inhaled corticosteroids and $\beta_{2}$-agonists, respectively, therefore confirming that they were suffering a very mild respiratory disease. This patient population may jeopardise the results of the study because the sample size was calculated assuming a mean duration of 120-180 days to the next exacerbation under clarithromycin, but, eventually, mean time to the next exacerbation was 300 and 350 days for levofloxacin and 
clarithromycin, respectively, and almost half of the population in both treatment arms had no relapse after $1 \mathrm{yr}$ of follow-up [6]. Stressing the importance of baseline severity of the disease, the results show a trend towards a longer exacerbation-free interval in patients treated with levofloxacin in the population of patients with an FEV $1<50 \%$ predicted [6]. Since only $28 \%$ of the included patients had an FEV1 $<50 \%$, this analysis was clearly underpowered to demonstrate such effect, if it really exists.

These results oblige us to look back, some 17 yrs ago, when the unanimously considered landmark study of antibiotic treatment in exacerbations of COPD was published [17]. The inclusion criteria required a COPD with an FEV1 $<70 \%$ and FEV1/forced vital capacity $<70 \%$, together with a total lung capacity $>80 \%$ and a negative bronchodilator test. However, the population was mainly composed of moderate-to-severe COPD patients with a mean FEV1 of only $33.9 \%$ predicted and a residual volume of $205 \%$ predicted. In this patient population, antibiotics performed better than placebo in exacerbations types I and II. Unfortunately, only the classification severity of exacerbations has been extensively used in posterior clinical trials, but the inclusion criteria have almost never been used again. Looking back some $13 \mathrm{yrs}$, the Italian trial also included patients with moderate-to-severe COPD with a mean FEV1 of $\sim 1.5 \mathrm{~L}$, which represents $35-40 \%$ predicted. In this study, there were clear and significant differences between the antibiotic and placebo treatments [18]. Moreover, in a new analysis of the same data, the authors demonstrated that patients with severe functional impairment are those who derive the greatest benefit from antibiotic therapy [19]. If a severe impairment in lung function is required to demonstrate differences between antibiotic and placebo, it will be very unlikely to observe differences between antibiotics (expected to be even smaller than between antibiotic and placebo) in milder patients. The results presented by LODE et al. [6] suggest that there is no additional benefit that justifies the wide use of quinolones in exacerbations of mild COPD patients without risk factors for therapeutic failure, which is in accordance with some guidelines $[4,5]$. This restriction in the use of quinolones in mild COPD patients would probably delay the development of bacterial resistance to these antibiotics.

The present study provides interesting results that may help the design of future studies. It is a step beyond the right direction by performing lung function to all patients in stable phase and including only chronic obstructive pulmonary disease cases [6]. The tendency towards better results in the most severe group will help researchers to select the adequate target population for future clinical trials. In addition, the use of the exacerbation-free interval as the primary outcome takes into account the unique characteristics of exacerbations of chronic obstructive pulmonary disease. This is particularly important, because most studies of antibiotics in exacerbations of chronic bronchitis have been modelled on pneumonia studies. No doubt, this study [6], together with the previous quinolone studies $[13,16]$ and the lessons learned from the past $[12,17,18]$, will guide the design of the new generation of clinical trials of antibiotics in exacerbations of chronic obstructive pulmonary disease [20].

\section{References}

1. Miravitlles M, Torres A. No more equivalence trials for antibiotics in exacerbations of COPD, please. Chest 2004; 125: 811-813.

2. Miravitlles M, Zalacain R, Murio C, et al. Speed of recovery from acute exacerbations of COPD after treatment with antimicrobials: results of a two-year study. Clin Drug Invest 2003; 23: 439-450.

3. Llor C, Naberan K, Cots JM, Molina J, Miravitlles M. Economic evaluation of the antibiotic treatment of exacerbations of chronic bronchitis and COPD in primary care centers. Int J Clin Pract 2004; (In press).

4. Balter MS, La Forge J, Low DE, Mandell L, Grossman RF. Canadian guidelines for the management of acute exacerbations of chronic bronchitis. Can Respir J 2003; 10: 3B-32B.

5. ALAT Work Group. Update to the Latin American Thoracic Society (ALAT) recommendations on infectious exacerbation of COPD. Arch Bronconeumol 2004; 40: 315325.

6. Lode H, Eller J, Linnhoff A, Ioanas M, and the Evaluation of Therapy-Free Interval in COPD Patients Study Group. Levofloxacin versus clarithromycin in COPD exacerbation: focus on exacerbation-free interval. Eur Respir $J$ 2004; 24 : 947-953.

7. Miravitlles M, Espinosa C, Fernández-Laso E, et al. Relationship between bacterial flora in sputum and functional impairment in patients with acute exacerbations of COPD. Chest 1999; 116: 40-46.

8. Bobadilla A, Guerra S, Sherrill D, Barbee R. How accurate is the self-reported diagnosis of chronic bronchitis? Chest 2002; 122: 1234-1239.

9. Anzueto A, Rizzo JA, Grossman RF. The infection-free interval: its use in evaluating antimicrobial treatment of acute exacerbation of chronic bronchitis. Clin Infect Dis 1999; 28: 1344-1345.

10. White AJ, Gompertz S, Bayley DL, et al. Resolution of bronchial inflammation is related to bacterial eradication following treatment of exacerbations of chronic bronchitis. Thorax 2003; 58: 680-685.

11. Patel IS, Seemungal TAR, Wilks M, Lloyd-Owen SJ, Donaldson GC, Wedzicha JA. Relationship between bacterial colonisation and the frequency, character, and severity of COPD exacerbations. Thorax 2002; 57: 759-764.

12. Chodosh S, Schreurs A, Siami G, et al. Efficacy of oral ciprofloxacin versus clarithromycin for treatment of acute bacterial exacerbations of chronic bronchitis. Clin Infect Dis 1998; 27: 730-738.

13. Wilson R, Allegra L, Huchon G, et al. Short and long-term outcomes of moxifloxacin compared to standard antibiotic treatment in acute exacerbations of chronic bronchitis. Chest 2004; 125: 953-964.

14. Miravitlles M. Exacerbations of chronic obstructive pulmonary disease: when are bacteria important? Eur Respir $J$ 2002; 20: 9s-19s

15. Sethi S, Evans N, Grant BJ, et al. New strains of bacteria and exacerbations of chronic obstructive pulmonary disease. $N$ Engl J Med 2002; 347: 465-471.

16. Wilson R, Schentag JJ, Ball P, Mandell L. A comparison of gemifloxacin and clarithromycin in acute exacerbations of chronic bronchitis and long-term clinical outcomes. Clin Ther 2002; 24: 639-652.

17. Anthonisen NR, Manfreda J, Warren CPW, Hershfield ES, Harding GKM, Nelson NA. Antibiotic therapy in exacerbations of chronic obstructive pulmonary disease. Ann Intern Med 1987; 106: 196-204.

18. Allegra L, Grassi C, Grossi E, et al. Ruolo degli antibiotici nel trattamento delle riacutizzazioni della bronchite cronica: risultati di uno studio italiano multicentrico. Ital J Chest Dis 1991; 45: 138-148.

19. Allegra L, Blasi F, de Bernardi B, Cosentini R, Tarsia P. Antibiotic treatment and baseline severity of disease in acute exacerbations of chronic bronchitis: a re-evaluation of previously published data of a placebo-controlled randomized study. Pulm Pharmacol Ther 2001; 14: 149-155.

20. Miravitlles M. Designing future clinical trials for acute exacerbations of chronic bronchitis. In: Allegra L, Blasi F, eds. Mechanisms and management of COPD exacerbations. Milan, Springer-Verlag, 2000; pp. 88-99. 